\title{
Distribución espacial de los daños producidos por los temporales del invierno 2014 en la costa norte de España: peligrosidad, vulnerabilidad y exposición Spatial distribution of damages from winter 2014 coastal storms in the northern coast of Spain: hazard, vulnerability and elements at risk
}

\author{
Carolina Garmendia Pedraja, Domingo F. Rasilla Álvarez \\ y Victoria Rivas Mantecón ${ }^{1}$
}

\begin{abstract}
RESUMEN
Durante el invierno de 2014 se produjo una sucesión de temporales que azotaron la costa galaico-cantábrica, generando cuantiosos daños, tanto en el medio natural como en equipamientos e infraestructuras, cuya restauración fue cuantificada en alrededor de 70 millones de $€$.

Dada la especial sensibilidad de las playas a la erosión, este tipo de ambientes ha centrado la mayor parte del análisis. Los resultados muestran que la distribución espacial de esos daños guarda más relación con la valoración de estos espacios por parte de la población que con la intensidad del fenómeno natural o los condicionantes geomorfológicos, confirmando que las consecuencias de los eventos climáticos extremos no dependen exclusivamente de la peligrosidad del proceso sino también de la vulnerabi-
\end{abstract}

${ }^{1}$ Carolina Garmendia Pedraja, Profesora Titular, Departamento de Geografía, Urbanismo y Ordenación del Territorio, Universidad de Cantabria, garmendc@unican.es, ORCID iD: http.//orcid.org/0000-0003-3282-7654. Domingo F. Rasilla Álvarez, Profesor Titular, Departamento de Geografía, Urbanismo y Ordenación del Territorio, Universidad de Cantabria, domingo.rasilla@unican.es, ORCID iD: http://orcid.org/0000-0003-2965-2822. Victoria Rivas Mantecón, Profesor Titular, Departamento de Geografía, Urbanismo y Ordenación del Territorio, Universidad de Cantabria, rivasv@unican.es, ORCID iD: http.//orcid.org/0000-0002-3516-5011. 
lidad (natural y social) de la zona geográfica afectada y de la cantidad y valor de los elementos en situación de riesgo.

Palabras Clave: norte de España; invierno 2013-14; temporal costero; mitigación de daños; riesgo.

\begin{abstract}
The succession of storms events that hit the Galician-Cantabrian coast during the winter of 2014 caused considerable damages, in both the natural environment and the infrastructures and equipment, whose restoration was worth around 70 million $€$ Taking in mind the sensibility of beaches to erosion, these types of environments focused much of the analysis. The results show that the spatial distribution of those damages keep a closer relationship with the greater appreciation of these spaces by the population rather than the magnitude of the natural phenomenon or the geomorphological background. That idea confirms that the consequences of the extreme climatic events do not depend exclusively on the process hazardousness but also on the vulnerability (natural and social) of the geographical area affected and the quantity and value of the elements at risk.
\end{abstract}

KEY WORDS: northern Spain; winter 2013-14; coastal storm; risk; damage mitigation.

Cómo citar este artículo / Citation: Garmendia Pedraja, Carolina, Rasilla Álvarez, Domingo F. y Rivas Mantecón, Victoria (2017): "Distribución espacial de los daños producidos por los temporales del invierno 2014 en la costa norte de España: peligrosidad, vulnerabilidad y exposición", Estudios Geográficos, LXXVIII/282, pp. 71-104.

\title{
1. INTRODUCCIÓN
}

La franja litoral constituye un ámbito muy complejo y extremadamente sensible ya que en ella la interacción entre procesos de muy diversa naturaleza (físicos, ecológicos, sociales, económicos, etc.) se muestra particularmente activa. Por un lado, experimenta constantes transformaciones, aleatorias temporal y espacialmente, debidas a fenómenos naturales; los temporales marinos, definidos como aquellas situaciones con oleaje de gran intensidad, corta duración y periodo de retorno del orden de décadas (Ayala y Olcina, 2002), desencadenan una respuesta inmediata, generando los cambios más drásticos en su evolución. Por otro, desde el punto de vista económico y social, el litoral se ha convertido en un ámbito estratégico para la economía, lo que se ha traducido en la concentración de una gran diversidad de usos (residencial, agrícola, pesquero, industrial, turístico, etc.), y en un espectacular crecimiento demográfico en su entorno. 
La combinación de ambos factores genera una situación de riesgo que previsiblemente aumentará con el tiempo si se consideran como hechos consumados las tendencias de litoralización en la distribución de la población y el ascenso del nivel del mar derivado del cambio climático.

A escala mundial y regional, la densidad de población en zonas costeras es significativamente superior a la del resto del territorio. En el año 2000 la población localizada en zonas costeras bajas, sujetas a potenciales impactos derivados del ascenso del nivel del mar (inundación y temporales con un periodo de retorno de 100 años), representaba el 10,9\%, con una densidad media de 241 personas $/ \mathrm{km}^{2}$, cinco veces superior a la media. Una estimación de la evolución en el tiempo proporciona una cifra de más de 1.000 millones (405 personas $/ \mathrm{km}^{2}$ ), alrededor del 12\% del total, para 2060 (Neumann et al., 2015). En Europa, donde un 16\% de la población reside en municipios costeros, casi un $20 \%$ de la línea de costa presenta un retroceso efectivo con un valor total de bienes económicos entre 500 y 1.000 millones de $€$ en el año 2000 (EUROSION, 2004). En este contexto, la contribución humana al incremento del riesgo en las zonas litorales se materializa en dos aspectos fundamentales: aumento de la exposición, a través de la instalación de cada vez más, y más caros, elementos materiales ligados a la población y sus actividades, es decir, de los elementos en situación de riesgo; y mediante la interferencia en los diversos parámetros que definen la peligrosidad del proceso natural. Si bien a una escala temporal de largo y medio plazo, una gran parte de los sistemas litorales afectados por los temporales recuperarían de forma natural el balance de sedimentos, la intervención humana ha intensificado los procesos erosivos en los tramos más vulnerables, especialmente aquellos constituidos por materiales no consolidados (playas, flechas de arena) o por material muy deleznable. A ello ha contribuido el deterioro y/o eliminación de los campos de dunas, la artificialización de las zonas de trasplaya, la proliferación de estructuras portuarias de defensa costera, etc., restringiendo su dinamismo, disminuyendo la disponibilidad y libre circulación de material sedimentario y, consecuentemente, su capacidad tanto para amortiguar los efectos negativos de los temporales como para permitir su regeneración natural.

Por lo que se refiere a la probable evolución de la peligrosidad del proceso natural, los impactos del cambio climático ya son perceptibles y, aunque los escenarios de futuro difieren en magnitud, hay consenso sobre el carácter inexorable del ascenso marino, que se traducirá en una intensificación de los problemas actualmente existentes en el litoral cantábrico (Cendrero et al., 2005; Chust et al., 2009; Chust et al., 2010). Mayor incertidumbre y controversia existe en relación con las proyecciones sobre la frecuencia, duración e intensi- 
dad de los episodios de oleaje extremo, especialmente desde una perspectiva regional, y variables en función del intervalo temporal considerado (Cid et al., 2015; Della-Marta y Pinto, 2009; Jordà et al., 2012; Marcos et al., 2012; Méndez et al., 2006).

Durante el invierno 2013-2014, una sucesión de temporales afectó la costa norte de España, concretamente a las Comunidades de Galicia, Asturias, Cantabria y País Vasco, causando víctimas mortales y cuantiosas pérdidas económicas.

El objetivo de este trabajo es determinar en qué medida la distribución espacial de los daños producidos por esos temporales responde a factores exclusivamente naturales (peligrosidad del proceso y/o vulnerabilidad de los distintos tramos de costa) o bien a condicionantes específicamente humanos tales como la exposición de elementos en riesgo y la «consideración social» de su valor.

Existen diversas aproximaciones a la evaluación de daños derivados de fenómenos naturales. Entre los más habituales se encuentran aquellos basados en la contabilización de los costes producidos por éstos (ex-post) (André et al., 2013; Meyer et al., 2013), tal como se llevará a cabo en este trabajo. No se trata, por tanto, de realizar un catálogo y/o una cuantificación completa y exhaustiva de todos los impactos producidos por los temporales, sino una evaluación del coste económico que han supuesto estos eventos. Así, la estimación del capital invertido en la reparación del litoral afectado es el único indicador objetivo disponible para «medir» el daño, en referencia al gasto generado como consecuencia del perjuicio ocasionado. En ningún caso se pretende hacer una asimilación entre conceptos tan distintos como impacto, daño y gasto en reparación, sino que se asume que las inversiones se han centrado en aquellos daños que se consideran «socialmente» relevantes y que no tienen por qué ser necesariamente ni más importantes ni más necesarios desde el punto de vista ambiental. En resumen, las inversiones en actuaciones puestas en marcha para paliar los efectos causados por los temporales permiten realizar una aproximación cuantitativa de los daños ocasionados en el litoral cantábrico.

2. CARACTERIZACiÓN DE LA DinÁMICA ATMOSFÉRICA DURANTE EL INVIERNO 2013-14

En la costa cantábrica, los vientos dominantes en el litoral son de componente NO, y son los temporales de esta dirección los que originan oleaje de gran altura; en la costa gallega de las Rías Bajas tienen también importancia 
los temporales asociados a vientos de componente SO. La situación oceanográfica del invierno 2013-2014 siguió las pautas características de este tipo de eventos en la zona: oleaje de fondo del $\mathrm{NO}$, con alturas máximas por debajo de los $12 \mathrm{~m}$ de altura de ola significante.

Desde el punto de vista de la dinámica atmosférica, la excepcionalidad radica en la sucesión de sistemas perturbados que cruzaron el Atlántico, con una frecuencia e intensidad muy superiores a lo habitual. Como reflejo de ello, el mapa de anomalías de la presión a nivel del mar correspondiente al trimestre diciembre-febrero (figura 1) muestra con claridad una amplia extensión con valores de - $18 \mathrm{hPa}$ en torno a las Islas Británicas (valores de presión muy inferiores a los habituales en esta época del año). Este mínimo de presión no sólo responde al reiterado tránsito de borrascas, sino a que alguna de ellas ha sido considerada como uno de los sistemas perturbados más potentes que ha cruzado el Atlántico desde que existen observaciones sinópticas.

FIGURA 1

\section{MAPAS DE LA ANOMALÍA DE LA PRESIÓN A NIVEL DEL MAR (IZQUIERDA) \\ Y VIENTO (DERECHA) CORRESPONDIENTES AL INVIERNO 2013-2014 (DESDE DICIEMBRE A FEBRERO)}
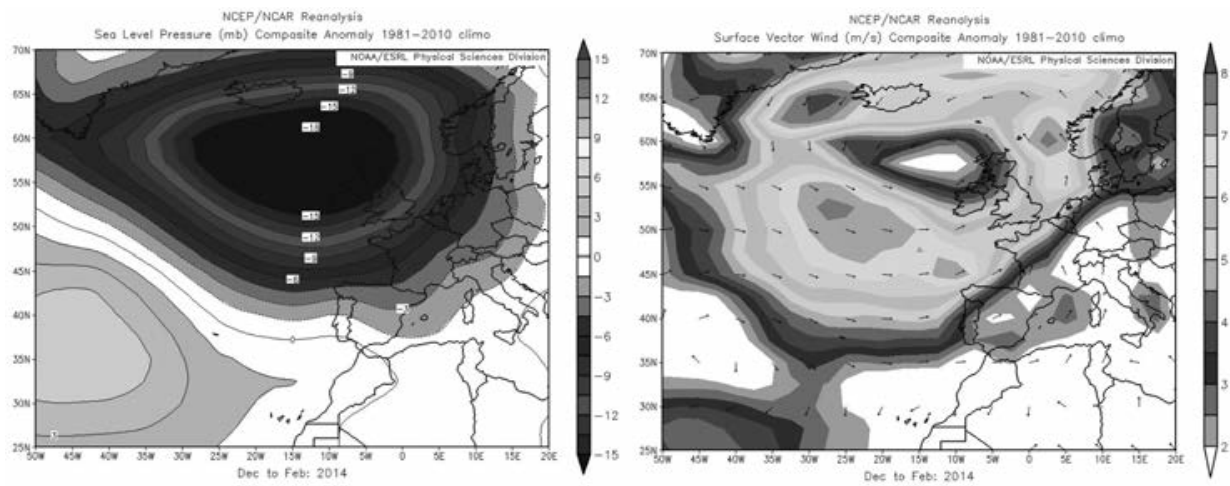

Fuente: NOAA/ESRL (2014).

En correspondencia con el mapa de presión a nivel del mar, el mapa de anomalías del viento en superficie (figura 1) muestra el típico patrón circular alrededor del núcleo del área de máximas anomalías de la presión, con tres áreas de intensificación del viento, una en el Estrecho de Dinamarca, otra 
frente a la costa noruega, y una tercera en mitad del Atlántico, entre los paralelos $45-55^{\circ} \mathrm{N}$, que coincidiría aproximadamente con el área génesis del oleaje de fondo que alcanza habitualmente las costas cantábricas. Nótese que en esta zona el viento habría adoptado una clara componente $\mathrm{NO}$, coincidiendo con la ya mencionada componente habitual del oleaje en esa zona.

A partir del análisis de datos de temporales en las costas del Cantábrico desde 1957 también se concluye que la excepcionalidad de los ocurridos en el invierno de 2013-14 radica, no tanto en su intensidad, como en su recurrencia (Conde Criado, 2014; Menéndez et al., 2014). Otros estudios muestran que, en su conjunto, ese invierno el Reino Unido experimentó el mayor número de temporales desde 1871 (Met Office, 2014a).

En este sentido, la erosión costera producida y los daños asociados a ésta dependen de las características del oleaje de la tormenta y su duración, pero también de las condiciones de partida del espacio litoral afectado, es decir, del estado de las playas previo a la tormenta, ya que se muestran mucho más vulnerables si han estado expuestas a los efectos de temporales recientes. Se trata de un efecto acumulativo por el que tormentas de menor intensidad, pero próximas en el tiempo, pueden causar mayor erosión que una de mayor magnitud.

\section{Metodología y fuentes}

La evaluación económica de los daños se ha estimado a partir del gasto en las indemnizaciones de los bienes asegurados y de las inversiones desarrolladas en el Plan Litoral.

El tipo, cantidad y distribución de los daños producidos por las situaciones descritas puede tener su origen en las características del proceso natural, en este caso una desigual distribución espacial de la intensidad del temporal, y/o estar condicionada por las características morfológicas, dinámicas o de utilización por parte del hombre de la zona afectada.

De acuerdo con este planteamiento, se analizará la relación existente entre el capital gastado en la mitigación de los daños con los factores que explicarían su distribución espacial: la particular intensidad de los temporales, desde el punto de vista oceanográfico, y las características específicas, físicas y humanas, de los distintos tramos de la costa afectada (figura 2). 
FIGURA 2

ESQUEMA CONCEPTUAL DE LA METODOLOGÍA UTILIZADA Y TIPOS DE DATOS UTILIZADOS
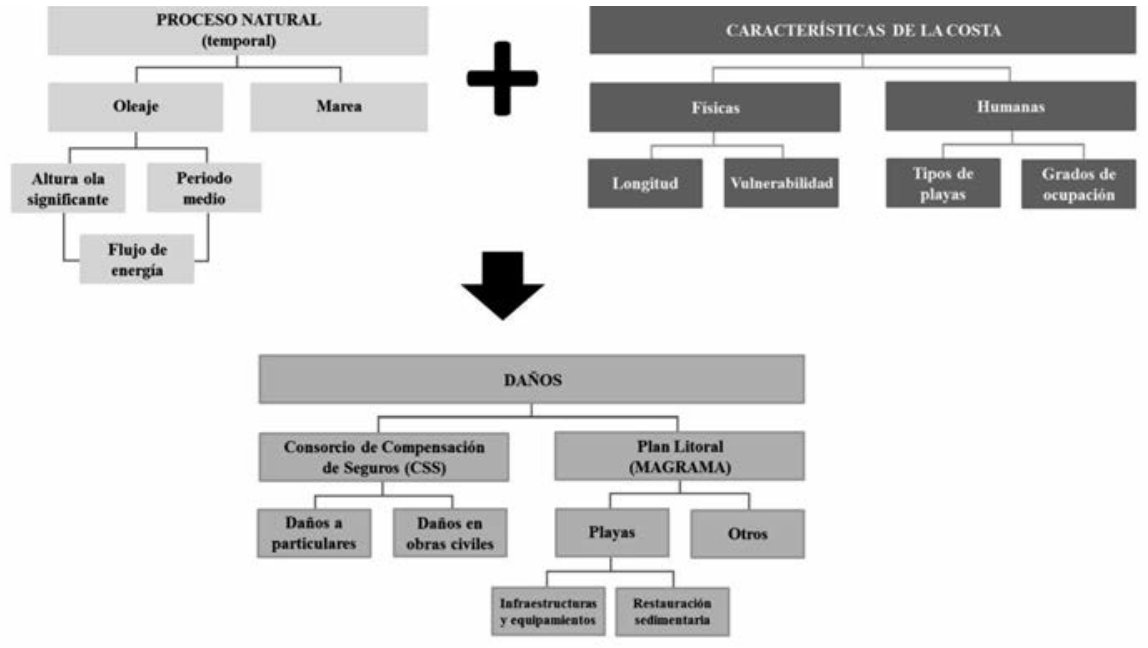

\subsection{Cuantificación del proceso natural}

Las dos manifestaciones oceanográficas más representativas de los temporales marinos son el oleaje y el nivel medio del mar, de los que, en principio, es posible obtener medidas directas, precisas y con elevada periodicidad.

La fuente de información más adecuada para la descripción del régimen del oleaje de un ámbito espacial son los datos recogidos por las boyas oceanográficas. Estas plataformas poseen instrumentos que registran de manera continua una serie de movimientos, que son procesados posteriormente para obtener una serie de parámetros típicos del oleaje, como son la altura significativa, el periodo medio y la dirección del oleaje. Sin embargo, al igual que cualquier otro instrumento remoto, son sensibles a problemas derivados de un funcionamiento incorrecto de sus sensores, así como a las propias condiciones ambientales, por lo que no es infrecuente que sus series temporales sufran lagunas, coincidentes en muchos casos con los episodios más violentos, que a su vez son los que suscitan más interés. Esta circunstancia afectó a algunas de las boyas de la red de Puertos del Estado fondeadas en el litoral cantábrico.

Para subsanar este problema se ha recurrido, como es habitual en estos casos, a la aplicación de datos de oleaje basados en modelos de reanálisis atmosférico y oceanográfico. Para este trabajo se ha utilizado el modelo ERA 
INTERIM (ECMWF, 2014; Berrisford et al., 2011), que ofrece valores, cada 6 horas $(00,06,12$ y 18 UTC), de un considerable número de parámetros meteorológicos y oceanográficos, con resolución espacial de $0,75^{\circ} \times 0,75^{\circ}$, desde 1979 hasta la actualidad. De este conjunto de datos, se han seleccionado aquellos que proporcionan la información necesaria para cuantificar la magnitud del proceso natural: la altura de ola significante (en metros) y el periodo medio de ola (en segundos). Con ambas variables se pueden obtener una serie de parámetros adicionales que sirven para cuantificar la intensidad de un temporal en términos de energía disipada. Uno de los más frecuentes es el flujo de energía, calculado a través de la siguiente fórmula:

$$
F=0,5 H_{m}^{2} T_{m}
$$

siendo:

F: Flujo de energía

$\mathrm{H}_{\mathrm{m}}$ : altura de la ola significante

$\mathrm{T}_{\mathrm{m}}$ : periodo medio de la ola

Por su parte, las variaciones del nivel del mar son medidas por los mareógrafos, situados habitualmente en los puertos más importantes del litoral. En este trabajo, una vez consultados los pertenecientes a la red de Puertos del Estado (2014), se han utilizado los que presentan series completas, los mareógrafos de Santander y Gijón.

\subsection{Caracterización del litoral}

La caracterización del litoral (figura 3) se ha basado, fundamentalmente, en tres tipos de variables: (a) la longitud de costa susceptible de ser afectada, en cada una de las siete provincias estudiadas, (b) el tipo de costa en función de su vulnerabilidad a la erosión y (c) una categorización de las playas, según distintos criterios que traducen la potencial afluencia de usuarios.

a) Los datos relativos a la longitud de costa, a escala provincial y municipal, se pueden obtener de diversas fuentes de información. Las diferencias entre ellas en ningún caso responden a errores de medición sino a la dificultad intrínseca de esta medida. En este trabajo se ha optado por utilizar la información que proporciona el Servicio de Delimitaciones Territoriales (Centro Nacional de Información Geográfica, 2014), procedente de las geometrías actualmente inscritas en el Registro Central de Cartografía (RCC) de los municipios costeros, por adecuarse mejor a su comparación con los datos de longitud de las playas, obtenidos también con base municipal. 
b) La vulnerabilidad de la zona costera frente a los temporales marinos está determinada por características de los sectores o grandes «unidades ambientales» que la constituyen. Inicialmente, se han distinguido dos grandes tipos de línea de costa: la costa sedimentaria, constituida por diferentes tipos de playas; y el resto, incluyendo tanto la artificial como la costa acantilada, menos dinámica y por tanto menos susceptible a los procesos de erosión ocasionados por los temporales. La longitud de las distintas playas del litoral estudiado, obtenida de la Guía de playas del MAGRAMA (2013), está sujeta a las consideraciones ya comentadas en el párrafo anterior. En cualquier caso, para el conjunto de litoral analizado, las discrepancias entre las distintas bases de datos representan un error en torno al $0,11 \%$ respecto al total de costa, y un $0,2 \%$ respecto al total de longitud de playa.

En una segunda aproximación, a partir de los datos proporcionados por la misma fuente, se han categorizado distintos tipos de playa en función de las características de su «fachada litoral», descrita en función de «lo que se encuentra detrás de la playa».

Simplificando las distintas situaciones posibles se han considerado tres categorías: playas no confinadas, con posibilidad de desplazamiento hacia el interior, tales como flechas y cordones litorales, cuya trasplaya está constituida por zonas de topografía suave, humedales, o campos dunares; confinadas de forma natural (playas de pie de acantilado); y playas confinadas artificialmente (fachadas urbanas y semiurbanas). Esta caracterización de las playas en función del grado y tipo de confinamiento es utilizada como indicador de su vulnerabilidad frente a la erosión debido a la mayor o menor posibilidad de intercambio sedimentario con su entorno y/o de migración tierra adentro, en situaciones de oleaje extremo.

c) La clasificación de las playas se ha obtenido igualmente de la base de datos de la Guía de playas del MAGRAMA, actualizada anualmente por los servicios periféricos de la Dirección General de Sostenibilidad de la Costa y del Mar. Esta base de datos ofrece información que va más allá de las propias características morfológicas y dinámicas de la playa, incluyendo una descripción de las condiciones de accesibilidad, seguridad, disponibilidad de servicios, etc. Así los indicadores que se han considerado relevantes para el tipo de trabajo presentado son:

- grado de urbanización, determinado en función de su ubicación y las condiciones del «entorno en el que se encuentra la playa respecto a la presencia de edificaciones». De acuerdo con este criterio se identifican tres tipos de playa: aislada, semiurbana, urbana; 
- existencia de paseo marítimo en la playa en el sentido longitudinal;

- grado de ocupación, nuevamente en las tres clases cualitativas que proporciona la fuente de datos: alto, medio y bajo.

Los dos primeros indicadores aportan información sobre las condiciones de su entorno próximo y, por tanto, de la existencia de equipamientos y servicios asociados al uso recreativo de las playas: accesos (escaleras, pasarelas peatonales, etc.), servicios (duchas, aseos, zonas infantiles, etc.) y obviamente los propios paseos (balaustradas, pavimento y muros), que constituyen los elementos en situación de riesgo. El último está más relacionado con la potencialidad de uso del propio sistema natural. La combinación de los tres proporciona una información completa sobre los bienes económicos directos, así como sobre los beneficios económicos derivados de su uso (turismo de sol y playa).

FIGURA 3

\section{CARACTERIZACIÓN DE LAS PLAYAS EN FUNCIÓN DE DISTINTOS CRITERIOS}

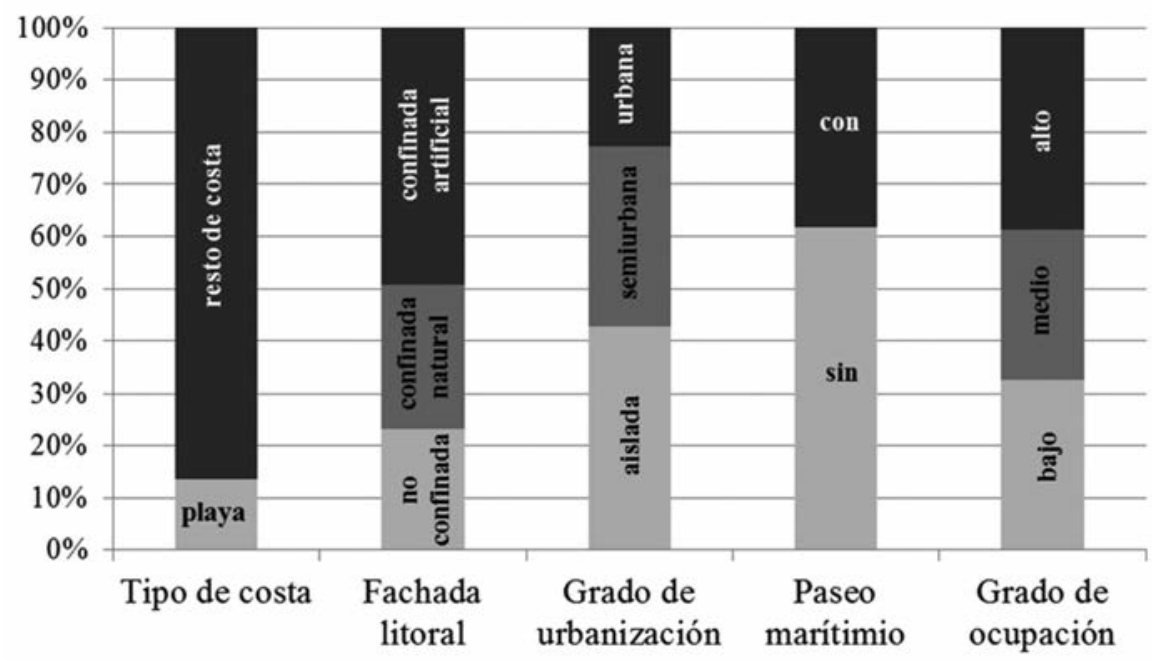

Fuente: MAGRAMA (2014).

\subsection{Estimación de los daños}

Esta labor se ha realizado a partir de los datos proporcionados por los dos organismos públicos que han centralizado estas intervenciones, el Consorcio de Compensación de Seguros, entidad adscrita al Ministerio de Economía y 
Competitividad, para bienes asegurados; y la Dirección General de Sostenibilidad de la Costa y del Mar, perteneciente al Ministerio de Agricultura, Alimentación y Medio Ambiente. Una parte de los gastos públicos ha sido asumida por los ayuntamientos, pero dada la dificultad de acceso a esta información derivada de su dispersión y su contribución mínima en el cómputo total, se ha considerado despreciable para este análisis.

a) El Consorcio de Compensación de Seguros (CCS, 2014a, 2014b) es el organismo estatal que da cobertura a los riesgos extraordinarios, con los que no corren las aseguradoras privadas. Es interesante subrayar que la protección no precisa que se hayan visto afectados un gran número de asegurados o de que dicho evento haya sido calificado de catástrofe. «Es posible que el siniestro afecte sólo a un asegurado, teniendo pleno derecho a la indemnización».

Su información resulta de gran interés porque permite relacionar los daños producidos por cada temporal de forma individualizada, es decir, permite determinar la relación entre intensidad del temporal y daño causado desde el punto de vista temporal (Rasilla et al., 2014). Es posible, además, comparar y extrapolar situaciones de similares características porque aplican criterios uniformes en sus evaluaciones.

Dentro de los riesgos extraordinarios definidos por el Consorcio, entre los derivados de «Fenómenos de la naturaleza», los temporales se encuadran en los «Embates de mar» (incluida la inundación) y cubrieron unas indemnizaciones de 36.484.451,88 € En este grupo definen hasta seis tipos de clase de riesgo, que se han agrupado en dos (figura 4):

- Riesgos de particulares: daños producidos a vehículos automóviles; viviendas, oficinas, comercios, almacenes y otros establecimientos en los que no se desarrolla una actividad industrial; y riesgos industriales (fábricas, talleres o almacenes).

- Riesgos de obras civiles: referidos a autopistas, autovías, carreteras, vías férreas y conducciones; puertos deportivos; resto de puertos (además de túneles; puentes; presas; explotaciones mineras y extracciones de aguas subterráneas).

b) El «Plan Litoral. Obras de reparación por temporales». Los daños ocasionados por los fuertes temporales que se suceden en el norte peninsular durante los meses de enero y febrero, hacen que el Gobierno promulgue, con carácter de urgencia, el Real Decreto-ley 2/2014, en el que se adoptan medidas urgentes para hacer frente a la catástrofe. El objetivo inicial de las actuaciones es la adopción «de un conjunto de medidas paliativas y reparadoras concordantes con las adoptadas anteriormente en ocasiones semejantes, para favore- 
cer el restablecimiento de los servicios, la reparación de los daños producidos y la vuelta a la normalidad de las zonas siniestradas por las tormentas».

La franja litoral del norte y noroeste peninsular es declarada zona de actuación especial para la restauración del Dominio Público Marítimo-Terrestre, adquiriendo carácter de emergencia las obras a ejecutar por el MAGRAMA, en los siguientes ámbitos:

- Restauración para asegurar la integridad y adecuada conservación del dominio público marítimo-terrestre, así como los trabajos complementarios para asegurar la sostenibilidad de la costa y mitigar los efectos de futuros temporales y galernas.

- Protección y conservación de los elementos que integran el dominio público marítimo-terrestre, en particular, la adecuación sostenible de arenales, sistemas y humedales litorales, recuperación y regeneración de los mismos, así como la realización, supervisión y control de estudios, proyectos y obras en la costa.

- Reparación y restauración de estructuras dañadas en el litoral, como paseos marítimos, accesos al dominio público, muros, etc.

Entre febrero y junio de 2014 se pone en marcha el denominado «Plan Litoral» que será desarrollado a través de la Dirección General de Sostenibilidad de la Costa y del Mar. El MAGRAMA, a través de su página Web, presenta y actualiza la información del Plan conforme se van ejecutando las obras, por provincia, municipio y, en su caso, tramo litoral concreto (DGSCM, 2014). Los datos utilizados en este trabajo corresponden a los cerca de 34 millones de $€$ repartidos entre las siete provincias afectadas presupuestadas en el Plan.

Para simplificar el análisis de la inversión realizada, ésta se ha clasificado en diversos tipos de intervenciones (figura 4):

- Restauración de playas: este epígrafe engloba todas las intervenciones orientadas a la recuperación de playas, sin diferenciar si esta rehabilitación tiene una finalidad ambiental o está motivada por una demanda social: dragado, recarga y redistribución de arenas (reperfilado de playas), restauración dunar, regeneración ambiental, etc.

- Infraestructuras y equipamientos de playas: las obras están destinadas al arreglo de elementos directamente relacionados con el uso de las playas, esto es, los accesos (rampas o escaleras), paseos marítimos, recalce y reparación de muros, mobiliario urbano, baños y duchas, etc.

- Reparaciones no ligadas a playas: en este apartado se incluyen aquellas actuaciones realizadas en los tramos de litoral sin playa: puertos, muros y espigones, acantilados, paseos marítimos y sendas que discurren por 
zonas acantiladas y mobiliario asociado a éstas, canalizaciones de regatos, reparación o demolición de construcciones contiguas (cetáreas, parques, miradores, edificios...), etc.

FIGURA 4

DISTRIBUCIÓN DE LOS GASTOS, POR TIPO DE ACTUACIÓN

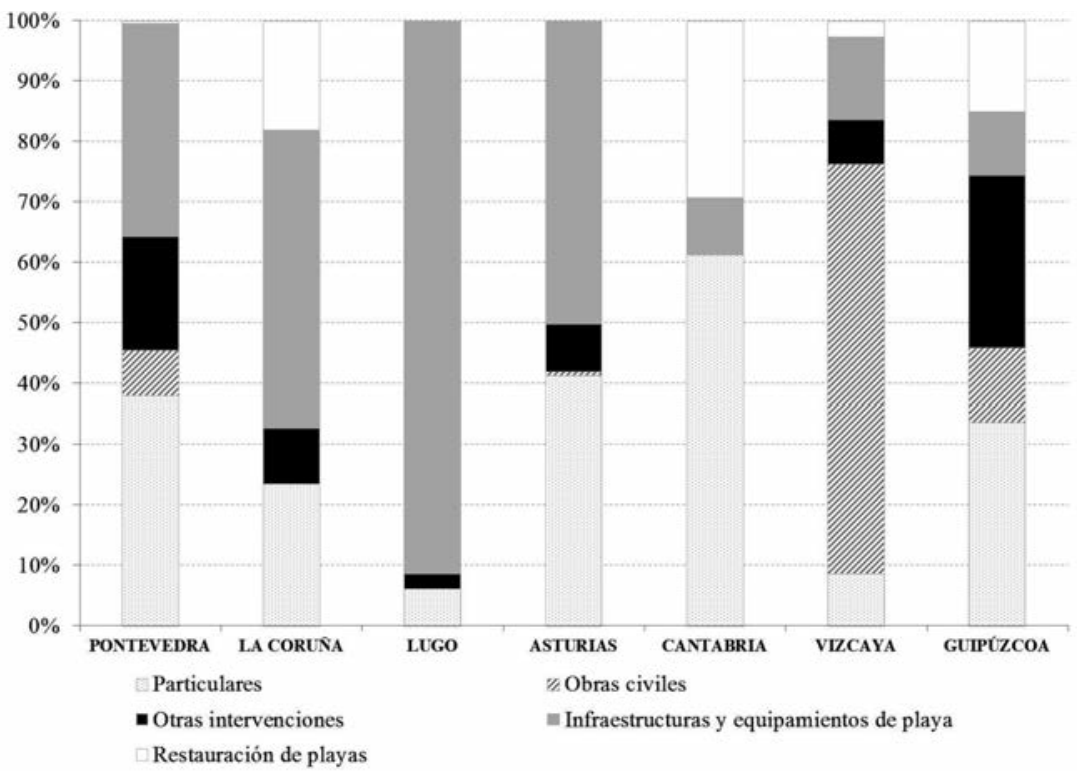

Fuente: DGSCM (2014) y CCS (2014b).

\section{Resultados}

\subsection{Intensidad de los temporales}

La evolución temporal de la energía del oleaje correspondiente a diferentes localidades de la costa cantábrica y gallega muestra tres episodios diferenciados en la ya citada sucesión de temporales (figuras 5 y 6), que fueron prácticamente simultáneos en toda la cornisa cantábrica y en la costa gallega:

- El primer episodio corresponde a la segunda quincena del mes de diciembre; su momento álgido fue el día 25/12/2013, correspondiendo al paso de la borrasca denominada «Kirk» (Institutfür Meteorolige, 2014), 
momento en el que los valores de energía casi alcanzaron los $400 \mathrm{~kW} / \mathrm{m}^{2}$ en zonas expuestas.

- El segundo episodio se desarrolló entre finales del mes de enero y toda la primera quincena del mes de febrero, pudiendo considerarse el episodio más singular por la sucesión de cinco temporales sin apenas solución de continuidad; dos de ellos igualaron la intensidad del episodio anterior («Nadja»: 1-2 de febrero y «Petra»: 5 de febrero), mientras que el correspondiente al 8 de febrero («Ruth») sobrepasó los $500 \mathrm{~kW} / \mathrm{m}^{2}$.

- Finalmente, el último episodio fue protagonizado por una única perturbación («Christine») que atravesó el N de España en la tarde noche del 3 al 4 de marzo, siendo, no obstante, el más intenso puesto que superó los $600 \mathrm{~kW} / \mathrm{m}^{2}$.

\section{FIGURA 5}

\section{MAPAS DE PRESIÓN CORRESPONDIENTES A LOS TRES EPISODIOS DE TORMENTA}

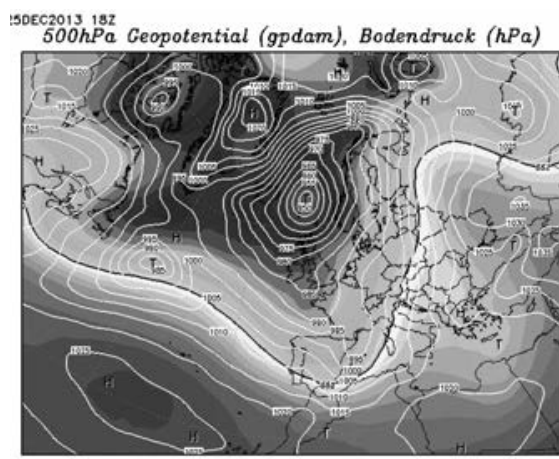

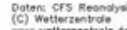

OAFEB2014 182

$500 \mathrm{hPa}$ Geopotential (gpdam), Bodendruck (hPa)

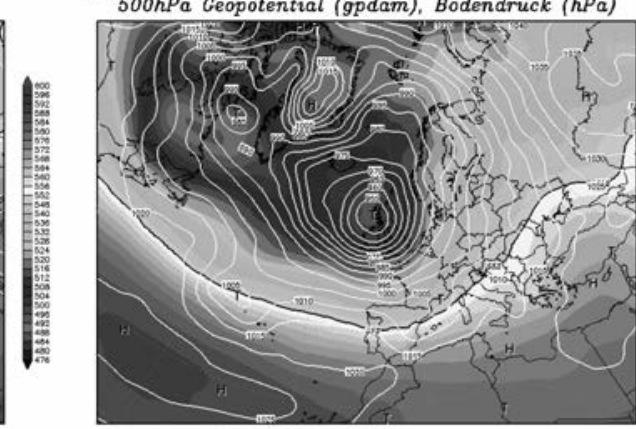

(c)

OJMNR20 $1418 \mathrm{z}$
$500 \mathrm{hPa}$ Geopotential (gpdam), Bodendruck (hPa)

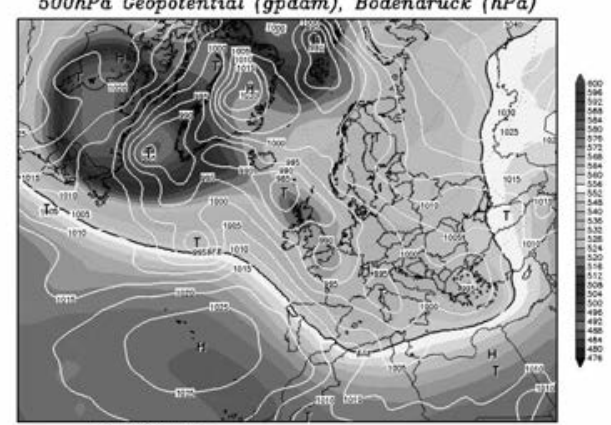

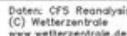

Fuente: Wetterzentrale (2014).

Estudios Geográficos, Vol. LXXVIII, 282, pp. 71-104, enero-junio 2017

ISSN: 0014-1496, eISSN: 1988-8546, doi: 10.3989/estgeogr.201703 
FIGURA 6

EVOLUCIÓN DEL OLEAJE EN DIVERSOS PUNTOS DEL LITORAL CANTÁBRICO Y DE LA COSTA GALLEGA

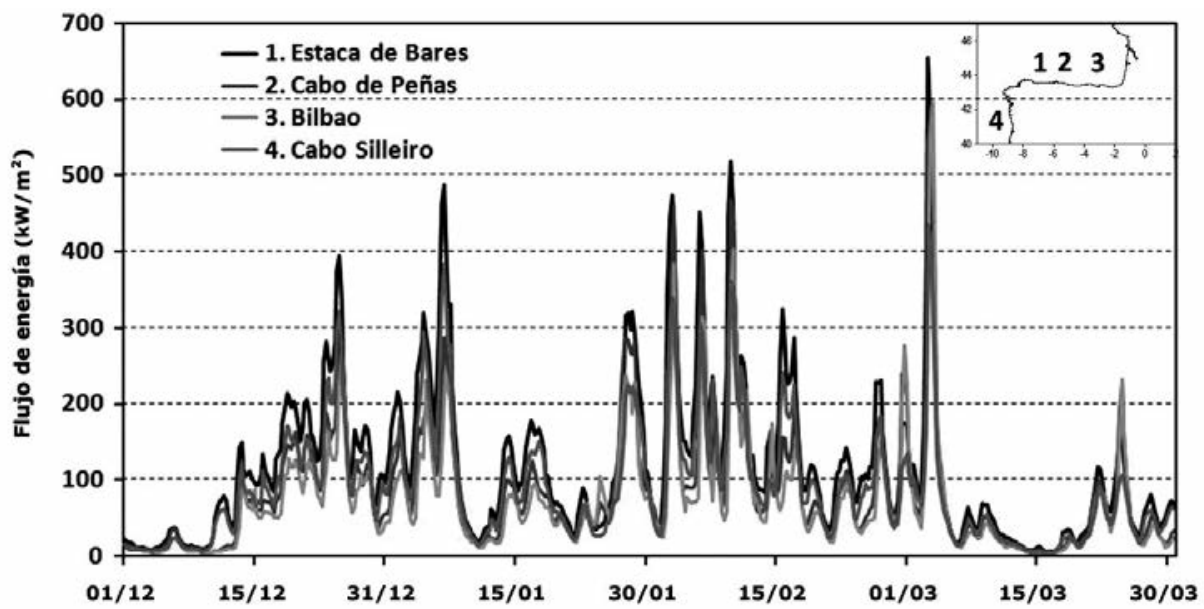

Fuente: ECMWF (2014)

El aspecto relevante para el análisis realizado en este trabajo es el reparto espacial de la energía generada por el oleaje. En los dos eventos que muestra la figura 7 se observa claramente la disminución paulatina de la energía a medida que se aproximaban al continente europeo y hacia el S. Dado que el oleaje procedía del NO (mar de fondo), la fachada occidental de Irlanda, SO de Gran Bretaña y O de Francia sufrieron un oleaje mucho menos energético que la costa cantábrica y atlántica de la Península Ibérica. En el ámbito peninsular, los valores más elevados se registraron al NO, en la costa de Galicia (correspondiente en líneas generales, al área cubierta por la boya de Estaca de Bares), detectándose un gradiente O-E a lo largo del Cantábrico, hasta un mínimo en la costa guipuzcoana, y otro N-S a lo largo de la costa gallega y portuguesa.

Pero la capacidad erosiva del oleaje está modulada, además, por las oscilaciones del nivel del mar, particularmente en costas mesomareales. A la escala temporal de análisis a la que se está trabajando, hay dos procesos que influyen en la evolución temporal del nivel del mar: la componente astronómica, resultado de la interacción entre la gravedad terrestre y la lunar; y la meteorológica, que provoca la sobreelevación del mar por efecto combinado de la presión atmosférica y el viento soplando sobre la superficie marina. 


\section{FIGURA 7}

VALORES DE LA ENERGÍA DEL OLEAJE CORRESPONDIENTES A 02/02/2014 (06 UTC, «RUTH») Y 03/03/2014 (18 UTC, «CHRISTINE»)

\section{Flujo de energía $\left(\mathrm{kW} / \mathrm{m}^{2}\right)$}
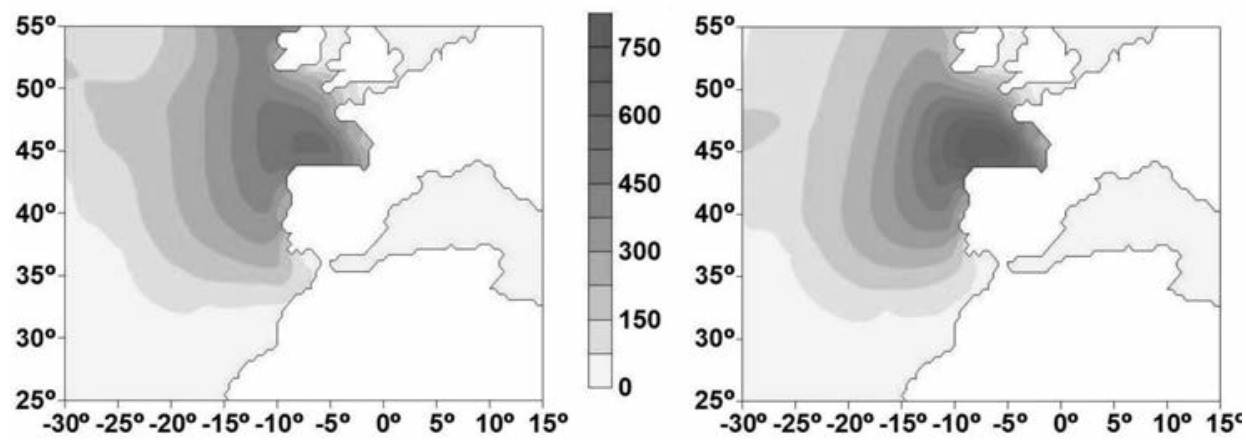

Fuente: ECMWF (2014).

En relación al primer aspecto, en la zona de estudio las mareas siguen un régimen semidiurno (aproximadamente una pleamar y una bajamar cada 12 horas), con amplitudes de 2-3 m entre mareas vivas y mareas muertas. A pesar de que la marea suele propagarse de $\mathrm{S}$ a $\mathrm{N}$ a lo largo de la costa atlántica, alcanzando mayor amplitud en la costa cantábrica oriental, la limitada anchura de la plataforma costera evita que los contrastes regionales, tanto en magnitud como en su evolución temporal, sean significativos (OSPAR Commission, 2000).

El segundo proceso es la marea meteorológica, que es la desviación relativa del nivel del mar (positiva en el caso de borrascas y negativa en el caso de anticiclones) con relación a la marea astronómica. Se produce cuando, durante el paso de una borrasca, la presión atmosférica baja (efecto de barómetro inverso) y el viento comienza a soplar hacia la costa, apilando el agua (wind set up). Su efecto se intensifica sobre costas con plataformas continentales amplias y costas bajas, condiciones ambas que no son frecuentes en la costa cantábrica, aunque, en líneas generales, su importancia es menor que la marea astronómica, dado que las mayores anomalías positivas oscilan entre los 30 y $40 \mathrm{~cm}$.

Un análisis pormenorizado, ejemplificado con la situación en la costa asturiana (figura 8), muestra que de los seis picos de energía del oleaje superior a los $400 \mathrm{~kW} / \mathrm{m}^{2}$ en el sector central del litoral cantábrico, sólo dos coincidieron con pleamares por encima de los $4 \mathrm{~m}$. Uno de ellos es el temporal del 2 de febrero, asociado al paso de la borrasca «Nadja», y el otro es el correspondiente 
al 3 de marzo, generado por «Christine». El primero coincidió con una pleamar de casi 4,70 m, y el segundo con una de 4,55 m. Los restantes cuatro picos de energía coincidieron con pleamares más reducidas, o directamente con bajamares, como el temporal generado por «Ruth» el 8 de febrero, con un pico próximo a los $500 \mathrm{~kW} / \mathrm{m}^{2}$, pero coincidente con una pleamar de solo 3,6 m.

Todo ello permite afirmar, de forma concluyente, que los daños ocasionados por los temporales en la costa analizada se debieron, tal y como expone el Real Decreto-ley 2/2014, a la coincidencia de un oleaje de gran altura, originado por las fuertes rachas de viento asociadas a las intensas borrascas, con una pleamar de carácter extraordinario.

\section{FIGURA 8}

EVOLUCIÓN DEL OLEAJE Y DEL NIVEL DEL MAR EN EL SECTOR CENTRAL DEL CANTÁBRICO

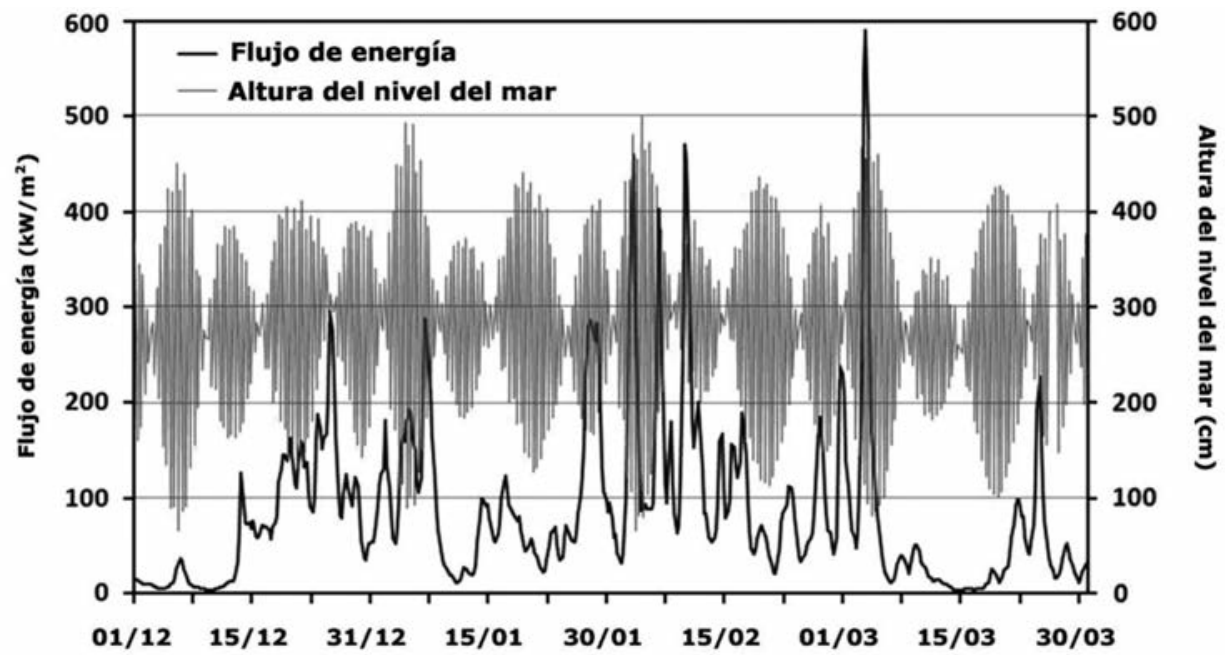

Fuente: ECMWF (2014) y Puertos del Estado (2014).

\subsection{Distribución geográfica de los daños}

Tanto la inversión realizada en la reparación de los daños causados por los temporales del MAGRAMA como las indemnizaciones pagadas por el Consorcio de Seguros (en términos absolutos) presentan una distribución espacial casi inversa a la energía del oleaje. La figura 9 muestra que los «daños» son 
mayores en aquellas provincias en las que los temporales alcanzan menor intensidad en términos de energía acumulada mientras que, por el contrario, la costa atlántica registra pérdidas muy inferiores.

FIGURA 9

DISTRIBUCIÓN ESPACIAL DE LOS GASTOS (ABSOLUTOS Y RELATIVOS) PARA LA MITIGACIÓN DE LOS DAÑOS CAUSADOS POR LOS TEMPORALES

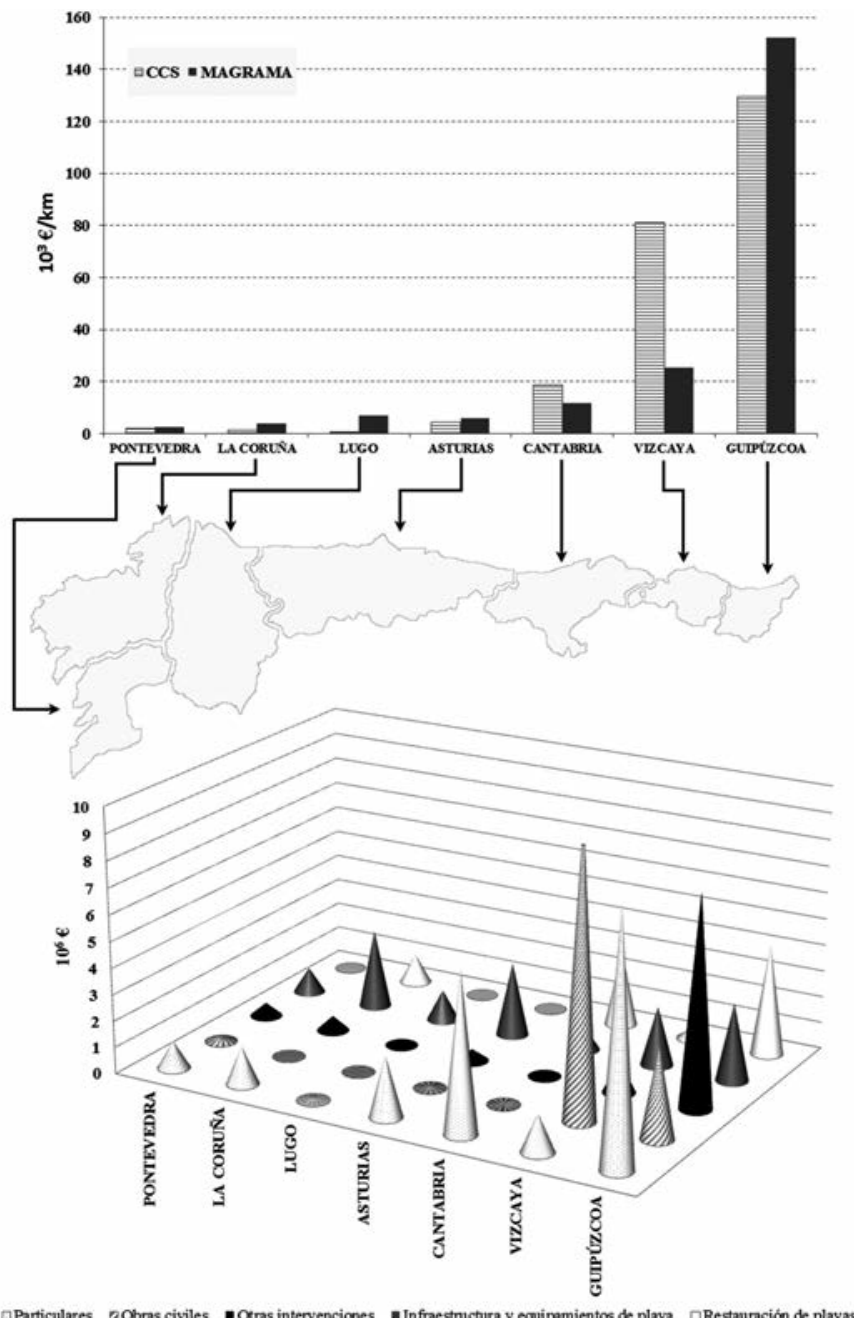

Fuente: CCS (2014b) y DGSCM (2014).

Estudios Geográficos, Vol. LXXVIII, 282, pp. 71-104, enero-junio 2017 ISSN: 0014-1496, eISSN: 1988-8546, doi: 10.3989/estgeogr.201703 
Obviamente, la primera aproximación consiste en relacionar las inversiones, desagregadas por provincias, con la longitud de costa correspondiente a cada una de ellas. La figura 9 muestra que no existe una relación directa entre ambos factores. La conversión a valores relativos $(€ \mathrm{~km})$ hace aún más evidente que la distribución de los «daños» poco tiene que ver con la intensidad de los temporales.

Esta, en principio sorprendente distribución, se mantiene si se analizan de forma independiente los gastos en las distintas partidas identificadas. En las indemnizaciones del Consorcio a obras civiles y particulares destacan, con gran diferencia, los daños reconocidos en Vizcaya y Guipúzcoa, respectivamente (figura 9): nuevamente el País Vasco concentra la mayor parte de las reclamaciones. Por lo que respecta a las inversiones del MAGRAMA, las cifras disminuyen de forma progresiva hacia el oeste, siendo casi insignificantes en las provincias atlánticas de Galicia.

\subsection{Vulnerabilidad natural}

Teniendo en cuenta, por tanto, que no aparece una correspondencia espacial entre la intensidad de los temporales y los daños producidos, se ha buscado una relación con los distintos atributos que caracterizan el litoral estudiado, algunos de los cuales determinan la mayor o menor vulnerabilidad frente a la erosión.

La orientación de la costa en relación a los frentes de oleaje no sirve para explicar la desigual distribución de daños en el litoral cantábrico donde las características son bastante uniformes, con un litoral básicamente rectilíneo y una orientación dominante hacia el norte.

Esta falta de relación no sorprende teniendo en cuenta que la mayor parte del litoral analizado está constituido por costa acantilada, con una menor susceptibilidad a los procesos de erosión. Además, predominan fundamentalmente los acantilados «duros», formados por rocas compactas, muy resistentes a la erosión y que no presentan problemas de retroceso. Por otro lado, los acantilados «blandos», constituidos por materiales poco coherentes, fácilmente erosionables y que presentan en la actualidad tasas anuales de regresión de orden decimétrico o incluso superiores, representan tramos muy limitados y con pocas actividades humanas asociadas (Rivas, 1991; Rivas y Cendrero, 1993).

Por lo que respecta a la costa directamente artificial, constituida por puertos, muros y espigones, paseos marítimos, la inversión es importante, pero a 
pesar del elevado coste de reparación de este tipo de construcciones, solo es dominante en la provincia de Guipúzcoa (figura 4) que acapara el $75 \%$ de la cantidad destinada a esta partida. Además, la mayor parte ha sido destinada a la reparación de los paseos y espigones de la ciudad de San Sebastián, siendo el resto de las intervenciones muy puntuales y mucho más modestas.

De hecho, aunque las playas suponen únicamente un 13,5\% del total de la costa (en ninguna de las provincias estudiadas llega al 20\%), son lógicamente las unidades ambientales en las que se han centrado la mayor parte de las actuaciones del MAGRAMA. Más del 60\% (unos $21 \times 10^{6} €$ ) de la inversión de Costas en todas las provincias afectadas y el $100 \%$ en Cantabria, se ha dedicado a la restauración de playas y/o de sus infraestructuras y equipamientos próximos (figura 4).

Sin embargo, en el análisis por provincias, tampoco parece establecerse una correlación aceptable entre la longitud de playa y la inversión realizada en ellas (figura 10). Nuevamente Guipúzcoa con la menor longitud de costa arenosa, consume la mayor parte del presupuesto (33\%); por el contrario, las provincias gallegas que, en conjunto representan más del $60 \%$ de la longitud de playa, no llegan al 25\%. Incluso sin considerar estos dos casos extremos, la ausencia de este patrón se manifiesta en el resto del litoral: Asturias, con una longitud de playa cinco veces superior a la de Vizcaya, ha invertido una cantidad muy similar en su recuperación. La discrepancia es aún mayor pues es precisamente en el litoral más occidental, en las provincias gallegas y asturiana, donde se observa una relación inversa entre la longitud afectada y la inversión realizada, mientras que en las provincias del País Vasco y Cantabria, el gasto es proporcionalmente muy superior a su longitud de playa.

Otros factores que deberían ser tenidos en cuenta para determinar la vulnerabilidad natural son la anchura y las características de la «tras-playa». Aunque no se ha llevado a cabo un análisis cuantitativo pormenorizado, las observaciones directas llevadas a cabo en las playas de Cantabria, indican que la anchura de las playas no ha sido un factor determinante en la ocurrencia de los daños. Playas con anchuras considerables, superiores a 100-200 m, como el Sardinero, en la ciudad de Santander, el Puntal de Laredo, o la playa de Somo, en Ribamontán al Mar, han sufrido una erosión tan intensa que el oleaje ha accedido a los paseos o edificios situados en sus proximidades en una proporción similar a las de Comillas, Suances o Brazomar (Castro Urdiales), significativamente más estrechas. 
FIGURA 10

LONGITUD Y GASTO EN PLAYAS

(\% RESPECTO AL TOTAL DE LA ZONA DE ESTUDIO)

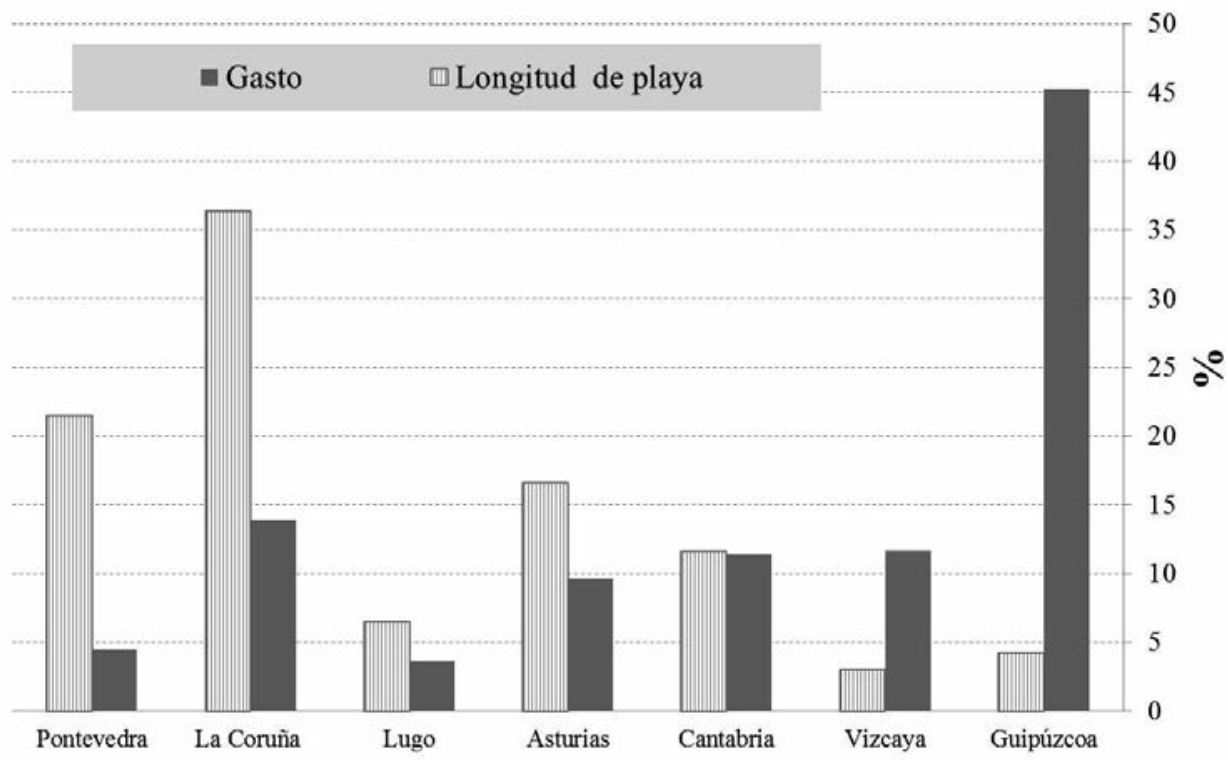

Fuente: Centro Nacional de Información Geográfica (2014) y DGSCM (2014).

Mayor relevancia podría tener el grado de confinamiento de la playa. Las playas confinadas no disponen de campos dunares con los que realizar el intercambio sedimentario de vital importancia en estas situaciones excepcionales, ni la posibilidad de migrar hacia el interior en momentos de máxima energía del oleaje. La ocupación del backshore y la disminución e incluso desaparición de los cordones de dunas, ha eliminado buena parte de la reserva natural de arena de las playas y de la alimentación recíproca entre ambos ambientes. Además, la sustitución de los cordones dunares que bordeaban la mayor parte de las playas cantábricas por estructuras rígidas favorece la mayor penetración de oleaje debido a la eliminación del efecto de disipación. En definitiva, la disminución notable del aporte y de la circulación libre de sedimentos (intercambios playa-duna) podrían ser las principales causas de vulnerabilidad frente a los temporales. Desde esta perspectiva, a priori sería lógico suponer que los daños de temporal hayan sido mayores, y con menor 
posibilidad de reversibilidad natural, en estas playas confinadas. Esto justificaría que la inversión se hubiera centrado en aquellas playas más vulnerables, aquellas que disponen de un volumen «restringido» de material.

Tanto teniendo en cuenta la inversión global del MAGRAMA en playas como la dedicada exclusivamente a la restauración del ambiente sedimentario, las playas no confinadas representan un porcentaje muy inferior $(6,8-3,13 \%)$ que el que les correspondería de forma proporcional a su número $(9,8 \%)$ o longitud $(23,2 \%)$ (figura 11 ; tabla 1$)$, lo cual, en principio, estaría en concordancia con la mejor disposición de este tipo de playas para enfrentarse a los temporales.

\section{FIGURA 11}

INVERSIONES SEGÚN LAS CARACTERÍSTICAS DE «TRAS-PLAYA»

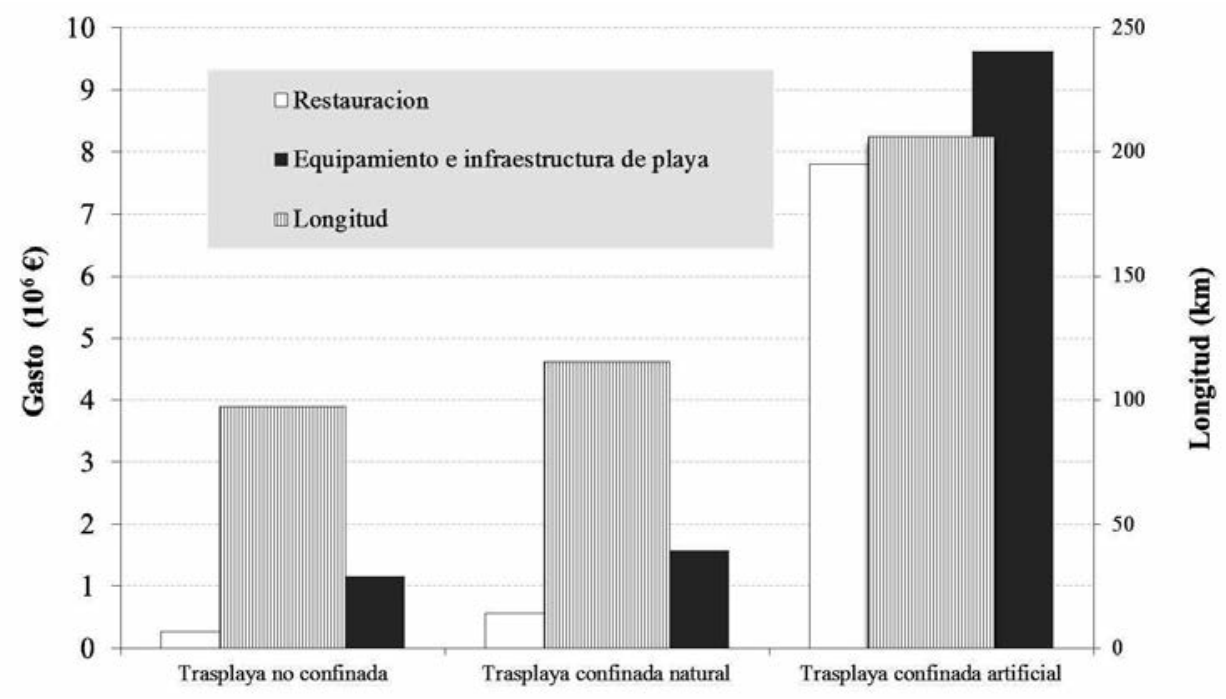

Fuente: MAGRAMA (2013) y DGSCM (2014).

En el caso contrario, de acuerdo con esta hipótesis, las playas con su límite superior fijo deberían haber sufrido más daños y/o precisarían de un mayor esfuerzo económico para su rehabilitación. Las playas confinadas de forma natural, que representan un $38 \%$ en número y un $27 \%$ en longitud, solo se han llevado un $10 \%$ de la inversión. Las confinadas, pero con estructuras artificiales, que representan aproximadamente la mitad de las playas estudiadas tanto en número como en extensión, absorben más del $80 \%$ de esta inversión. Se ob- 
tiene un resultado muy similar si se considera únicamente el gasto en restauración (90\% para las confinadas artificiales), es decir, exclusivamente en restablecer las condiciones de perfil previas a los temporales (figura 11; tabla 1).

TABLA 1

DISTRIBUCIÓN DE LOS DISTINTOS TIPOS DE INVERSIÓN EN PLAYAS EN FUNCIÓN DE SU VULNERABILIDAD

\begin{tabular}{l|r|c|c|c|c|c|c|c|c|c}
\hline \multirow{2}{*}{\multicolumn{1}{c}{ Tipo de play }} & \multicolumn{2}{|c|}{$\mathrm{N}^{\mathbf{2}}$} & \multicolumn{2}{c|}{ Longitud } & \multicolumn{2}{c|}{ Inversión total } & \multicolumn{3}{c}{ Restauración } \\
\cline { 2 - 11 } & \multicolumn{1}{c|}{$\mathrm{N}^{\mathbf{0}}$} & $\%$ & $\mathrm{~km}$ & $\%$ & $10^{6} €$ & $\%$ & $€ \mathrm{~km}$ & $10^{6} €$ & $\%$ & $€ \mathrm{~km}$ \\
\hline no confinada & 117 & 9,84 & 97,2 & 23,2 & 1,43 & 6,82 & 14,75 & 0,27 & 3,13 & 2,78 \\
\hline confinada natural & 456 & 38,35 & 114,9 & 27,4 & 2,14 & 10,19 & 18,62 & 0,56 & 6,56 & 4,93 \\
\hline confinada artificial & 616 & 51,81 & 206,3 & 49,3 & 17,43 & 82,98 & 84,49 & 7,80 & 90,31 & 37,83 \\
\hline TOTAL & 1189 & 100 & 418,5 & 100 & 21,0 & 100 & 50,19 & 8,64 & 100 & 20,65 \\
\hline
\end{tabular}

Fuente: MAGRAMA (2013) y DGSCM (2014).

Una posible explicación de esta diferencia es que las playas situadas en ensenadas protegidas por promontorios o al pie de los acantilados son, en general, de reducidas dimensiones (media alrededor de $200 \mathrm{~m}$ ) y apenas presentan interferencias humanas directas (instalaciones eventuales ligadas al uso estival) por lo que su pendiente está lógicamente adaptada a los ciclos estacionales de los agentes de modelado. De este modo, se consideraría previsible que después de los intensos episodios erosivos producidos durante el invierno, la reconstrucción de su perfil de equilibrio se produzca, de forma espontánea, durante los periodos de calma, en un lapso corto de tiempo.

Por el contrario, en las playas confinadas artificialmente mediante paseos, muros o edificaciones, la alteración humana del balance sedimentario no permitiría asegurar que el arrastre de sedimento producido durante los temporales retorne a corto plazo, por lo que se consideraría necesaria la inversión en alimentación y redistribución de sedimentos.

Otra interpretación, no excluyente con la anterior, dada la lógica coincidencia entre el tipo de trasplaya urbana o semiurbana con la presencia y cantidad de bienes «económicos» así como con su potencial de cara a la función recreativa, sugiere que tal vez la justificación de la inversión no está tan relacionada 
con la potencialidad de la playa para defenderse y/o recuperarse como por el distinto «valor» otorgado a las diferentes playas en función de su uso potencial.

\subsection{La acogida de los espacios de playa}

Con objeto de contrastar esta última hipótesis, se ha utilizado una aproximación más directa para «medir»el grado de antropización de la playa y su capacidad de uso, ambas función, en gran medida, de la ubicación de la playa. La clasificación contempla tres categorías: playa urbana, playa semi-urbana y playa aislada. Otro indicador de utilidad es la existencia de un paseo marítimo adyacente a la playa cuyo coste de mantenimiento es considerable.

TABLA 2

INVERSIÓN EN FUNCIÓN DEL GRADO DE URBANIZACIÓN DE LA PLAYA

\begin{tabular}{|c|c|c|c|c|c|c|c|c|}
\hline \multirow{3}{*}{ Tipo } & \multirow{2}{*}{\multicolumn{2}{|c|}{ Playas }} & \multicolumn{6}{|c|}{ Inversión en mitigación de daños en playas } \\
\hline & & & \multicolumn{4}{|c|}{ Total } & \multirow{2}{*}{$\begin{array}{c}\begin{array}{c}\text { Restauración } \\
\text { sedimentaria }\end{array} \\
106 €\end{array}$} & \multirow{2}{*}{$\begin{array}{c}\begin{array}{c}\text { Infraestructuras } \\
\text { y equipamientos }\end{array} \\
106 €\end{array}$} \\
\hline & $\mathrm{N}^{\mathrm{o}}$ & $\mathrm{km}$ & $\mathrm{N}^{0}$ & $\mathrm{~km}$ & $\mathrm{~km} 10^{6} €$ & $10^{6} € \mathrm{~km}$ & & \\
\hline Urbana & 243 & 95,4 & 73 & 46,8 & 12,9 & 0,3 & 6,12 & 6,85 \\
\hline Semiurbana & 392 & 144,1 & 96 & 55,1 & 6,2 & 0,1 & 1,89 & 4,31 \\
\hline Aislada & 554 & 179 & 67 & 41,2 & 1,8 & 0,0 & 0,63 & 1,17 \\
\hline Total & 1189 & 418,5 & 236 & 143,1 & 21,0 & 0,1 & 8,64 & 12,33 \\
\hline Con paseo & 330 & 160,4 & 117 & 84,38 & 17,2 & 0,2 & 7,4 & 9,8 \\
\hline
\end{tabular}

Fuente: MAGRAMA (2013) y DGSCM (2014).

De un total de 1.189 playas contabilizadas en el litoral estudiado, que cubren una longitud de 418,5 km, la inversión se ha dedicado exclusivamente a 236 (el 20\% del total) que representan grosso modo un tercio de la longitud de playa del conjunto del litoral (tabla 2). De ellas, el 31\% son consideradas playas urbanas y a pesar de que su longitud (unos $46,8 \mathrm{~km}$ ) representa apenas un $33 \%$ del total, han concentrado dos tercios de las inversiones. En sentido con- 
trario, en las clasificadas como aisladas, que representan casi otro tercio de la longitud de playa intervenido, la inversión solo ha supuesto un 10\% del total dedicado a este tipo de medios. Igualmente, y como es lógico esperar, las playas equipadas con paseo marítimo, a pesar de que representan menos del $30 \%$ en número y del 40\% en longitud, acaparan el 82\% de la inversión. En resumen, la inversión proporcional $(€ \mathrm{~km})$ en la mitigación de los daños en playas urbanas $\left(0,28 \times 10^{6} € \mathrm{~km}\right)$ es siete veces superior al correspondiente a las playas aisladas.

FIGURA 12

\section{CARACTERÍSTICAS DE LAS INVERSIONES SEGÚN EL TIPO DE PLAYA}

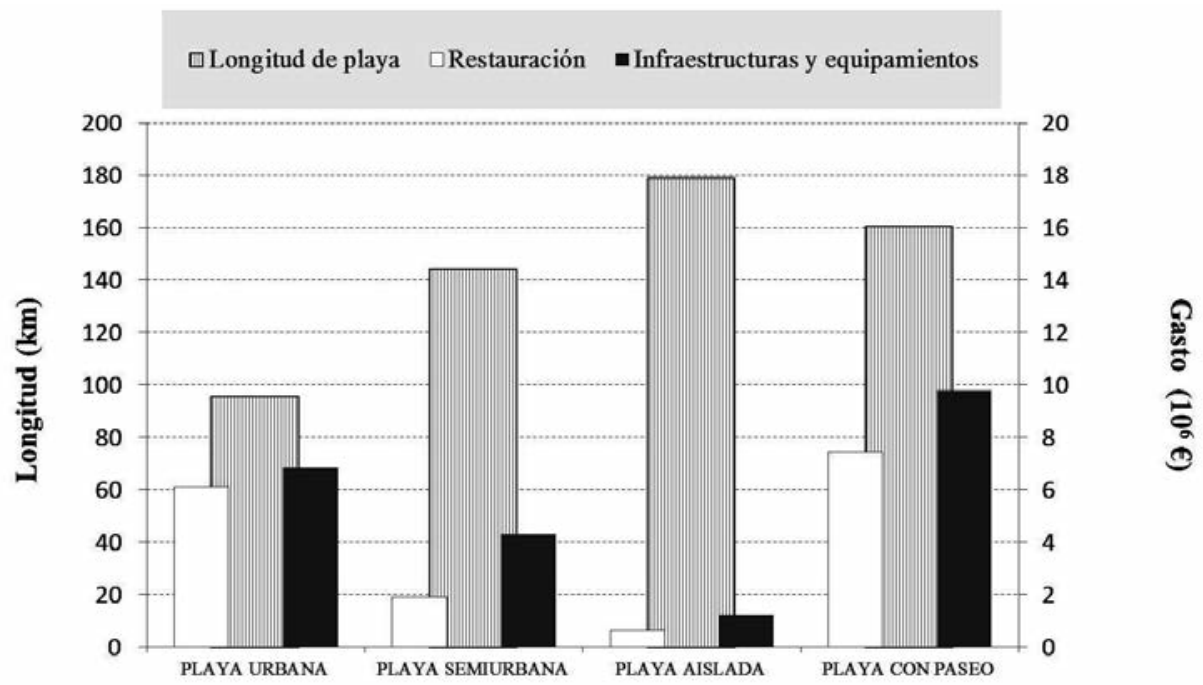

Fuente: MAGRAMA (2013) y DGSCM (2014).

En relación con la distribución interna del capital invertido, el mayor porcentaje, alrededor del 60\%, ha ido destinado a la reparación de los daños producidos en los «bienes económicos» situados sobre ellas y en sus entornos. Aunque esta afirmación es válida para todos los tipos de playa identificados (figura 12) la diferencia entre gastos en infraestructura y mobiliario, por un lado, y en la restauración del ambiente sedimentario, por otro, es menor precisamente tanto en las playas urbanas como en las que tienen paseo marítimo. Esto pone de manifiesto que el interés en la recuperación de estas playas no se restringe únicamente al mantenimiento de los bienes directos afectados (fa- 
chadas marítimas deterioradas) sino que se refiere también a la consecución de unas condiciones de playa adecuadas para el uso recreativo (tomar el sol, baño, deportes náuticos, etc.). El atractivo turístico de las zonas litorales lleva implícito el mantenimiento de una mínima calidad ambiental que hace de la playa un recurso natural con una gran valoración por parte de la sociedad. Al mismo tiempo es la propia playa el elemento básico, el ingrediente imprescindible, para el desarrollo de las actividades económicas de su entorno.

La importancia del turismo en la economía española, tanto en lo referente a su contribución al PIB como al empleo, es un hecho más que contrastado. Según el Ministerio de Hacienda (2012) las actividades turísticas que, en su mayoría se desarrollan en el litoral, contribuyen a más del 10\% del PIB y afectan al $12 \%$ de la población activa española. En el litoral estudiado, aunque el denominado turismo de sol y playa no presenta los rasgos masivos propios del modelo típico del Mediterráneo, también representa una fuerte motivación en la llegada de visitantes, especialmente en periodo estival. La actividad turística asociada a estos entornos depende directamente de la calidad del recurso playa, además de la calidad de los servicios ofertados por ésta, de modo que su degradación ambiental, la disminución de su calidad, supone automáticamente una pérdida de atractivo que repercutirá negativamente en los beneficios de dicho sector de actividad.

Una forma sencilla de constatar ese argumento es que las consideradas playas con alto grado de ocupación (MAGRAMA, 2014) han consumido el 80\% del presupuesto total (tabla 3) con una inversión proporcional más de 10 veces superior al de las playas poco frecuentadas.

TABLA 3

INVERSIÓN EN PLAYAS SEGÚN SU GRADO DE OCUPACIÓN

\begin{tabular}{|c|c|c|c|c|}
\hline \multirow{2}{*}{$\begin{array}{c}\text { GRADO } \\
\text { DE OCUPACION }\end{array}$} & \multirow{2}{*}{$\begin{array}{c}\text { Longitud } \\
\%\end{array}$} & \multicolumn{3}{|c|}{ Inversión en playa } \\
\hline & & $10^{6} €$ & $\%$ & $€ \mathrm{~m}$ \\
\hline ALTO & 38,64 & 16,8 & 79,77 & 103,75 \\
\hline MEDIO & 28,76 & 3,08 & 14,44 & 25,22 \\
\hline BAJO & 32,59 & 1,3 & 5,78 & 8,92 \\
\hline TOTAL & 100 & 21,0 & 100 & 50,25 \\
\hline
\end{tabular}

Fuente: MAGRAMA (2013) y DGSCM (2014). 
De hecho, aumentando el detalle del análisis, se observa que el 60\% $\left(12,5 \times 10^{6} €\right)$ de la inversión en playas se ha centrado únicamente en $20 \mathrm{~km}$, correspondientes a playas con una privilegiada situación geográfica desde el punto de vista de su potencialidad de uso. Es el caso de las playas de Panxón (Nigrán) en Pontevedra; Miño en La Coruña; San Lorenzo (Gijón) y Salinas (Castrillón), en Asturias; las playas de la ciudad de Santander y Laredo, en Cantabria; Karraspio y Bakio, en Vizcaya; y Zarauz, La Concha y Zurriola (San Sebastián) y Hondarribia en Guipúzcoa. Aquellas que no están localizadas en la propia capital de su provincia, se encuentran muy próximas a ésta y con buena comunicación (menos de 60' y de 30' en muchos casos) con los principales núcleos de población: Pontevedra y Vigo (a menos de 20 km y 30' de Pantxon), La Coruña y Ferrol (ambas a menos de 28 km y 30' de las playas de Miño) y, en menor medida Santiago de Compostela (a unos $75 \mathrm{~km}$ y 45'); Avilés (a 4 km de Salinas); Bilbao (a 25 km y 25' de Bakio); Irún y Pasajes (cerquísima de Hondarribia). Todas ellas disponen de paseos marítimos; fácil accesibilidad, tanto por medios privados (amplios aparcamientos) como públicos (transporte urbano y/o interurbano); y están equipadas con todo tipo de servicios (duchas, aseos, zona infantil, socorristas), así como dotadas de una gran oferta de establecimientos hosteleros (bares, restaurantes y hoteles) en sus alrededores. La inversión en ellas ha oscilado entre 0,5 y más de 2 millones $€$ playa.

TABLA 4

DISTRIBUCIÓN DE LA POBLACIÓN EN EL LITORAL

\begin{tabular}{l|c|c|c|c}
\hline PROVINCIAS & $\begin{array}{c}\text { Población costera } \\
\text { respecto al total } \\
(\%)\end{array}$ & $\begin{array}{c}\text { Población } \\
\text { "20 playas" } \\
\text { seleccionadas } \\
\text { (habitantes) }\end{array}$ & $\begin{array}{c}\text { Población } \\
\text { "20 playas" } \\
\text { respecto costera } \\
(\%)\end{array}$ & $\begin{array}{c}\text { Población } \\
\text { "20 playas" } \\
\text { respecto al total } \\
(\%)\end{array}$ \\
\hline GUIPÚZCOA & 46,86 & 301.383 & 91,14 & 42,71 \\
\hline VIZCAYA & 52,81 & 357.173 & 58,67 & 30,99 \\
\hline CANTABRIA & 66,27 & 195.291 & 50,01 & 33,14 \\
\hline ASTURIAS & 45,87 & 384.690 & 77,28 & 35,45 \\
\hline LUGO & 16,62 & 0 & 0,00 & 0,00 \\
\hline CORUÑA & 64,38 & 325.817 & 44,18 & 28,44 \\
\hline PONTEVEDRA & 74,73 & 396.929 & 55,34 & 41,36 \\
\hline
\end{tabular}

Fuente: INE (2014). 
De hecho, los habitantes de los municipios costeros constituyen el 50\% del total de sus provincias y poseen una densidad muy superior. Sin embargo, es el número de habitantes que reside en el entorno de las 20 playas mencionadas, el que arroja unas cifras más significativas (tabla 4): casi el 60\% de la población litoral y más del 30\% del total provincial se asienta en el entorno de estas 20 playas. Esta cifra es aún más espectacular en Guipúzcoa y Asturias donde los residentes, potenciales usuarios de las playas consideradas, suponen el $91 \%$ y $77 \%$ de la población costera, respectivamente.

En definitiva, parece evidente que, en la distribución espacial del gasto en medidas de recuperación de los daños causados por los temporales, la potencialidad de uso representa un factor fundamental.

\section{DiSCUSIÓN Y CONCLUSIONES}

El análisis realizado pone de manifiesto que la distribución espacial de estos daños no guarda relación con la intensidad del fenómeno natural que los generó. La distribución espacial de la energía del oleaje muestra una disminución progresiva de intensidad desde las costas gallegas al litoral guipuzcoano (figura 7); por el contrario, el patrón geográfico de las cifras de daños, tanto considerados en términos absolutos como de forma proporcional a la longitud de costa (figura 9) o de playa (figura 10), indican un aumento progresivo hacia el Este.

De acuerdo con estos datos, queda en evidencia que las consecuencias de estos procesos no dependen exclusivamente de la peligrosidad del proceso natural sino también de la combinación de las características físicas y humanas de la zona geográfica afectada: su vulnerabilidad (natural y social) y la cantidad y precio de los elementos en situación de riesgo.

La especial sensibilidad de las playas a la erosión producida por los temporales ha conducido a centrar la mayor parte del análisis en este tipo de ambientes. Los resultados obtenidos muestran que la distribución de los considerados «daños» tiene menor relación con los condicionantes naturales (definidos en función de las características de la trasplaya) que con la valoración de estos espacios por parte de la población, incluyendo tanto los bienes directos afectados (dotaciones y servicios para el acceso y el uso público de la costa) como su potencialidad de uso. Así, el 60\% del presupuesto en playas se ha invertido en reparar daños directos y esto hace que, obviamente, sean mayores en las playas con más elementos en situación de riesgo, las calificadas como playas urbanas. El 40\% restante se ha invertido en recuperar el equili- 
brio natural de las playas y dunas (restablecimiento de perfiles, realimentación de arena, etc.) pero no de todas las playas afectadas sino solo de aquellas que tienen un potencial de uso que indirectamente produce beneficios económicos a corto plazo, generalmente asociados a actividades terciarias relacionadas con el ocio.

En los últimos años, se han desarrollado una gran variedad de metodologías orientadas a cuantificar el «valor» de los distintos componentes y funciones ambientales (Constanza et al., 1997). Algunos de estos valores son evidentes y tienen reflejo directa o indirectamente en el mercado: son los valores de uso. Pero hay otros que no lo son tanto y que derivan del «mero hecho de su existencia». Concretamente los productos o servicios generados por las playas se pueden agrupar, a grandes rasgos, en tres clases (Cendrero et al., 2005):

- estructuras o bienes con precio de mercado;

- elementos naturales sin valor de mercado pero que son la base de actividades económicas ligadas al sector de turismo y ocio;

- unidades naturales, no ligadas de manera directa a actividades productivas, valiosas en sí mismas y que además proporcionan servicios ambientales esenciales tales como la concentración de biodiversidad o, en el caso que nos ocupa, la amortiguación de temporales ofreciendo protección a la costa.

Estos servicios corresponden a las funciones básicas otorgadas a estos ambientes y concuerdan, por tanto, con las líneas de intervención explícitas de la Administración de Costas: defensa del litoral, hábitat para la flora y fauna silvestres y zona de esparcimiento y uso público social.

En este contexto, los daños producidos en el valor de uso directo son relativamente fáciles de cuantificar en unidades monetarias, es decir, tienen una sencilla asignación de precio. A grandes rasgos se podría considerar que la inversión en infraestructuras, equipamientos y mobiliario urbano equivaldría a este tipo de daños económicos. En el caso de estudio analizado se consideró prioritario su mantenimiento en condiciones óptimas para asegurar el acceso, tránsito y disfrute de las playas durante la temporada alta turística.

Los valores no contabilizados en el mercado responderían, en mayor medida, al interés en restaurar las condiciones sedimentarias de determinados entornos, en función de su potencialidad de uso, y del mantenimiento de unas condiciones ambientales (pendiente de la playa, calidad del sedimento, etc.), aspectos que suelen dar lugar a las codiciadas acreditaciones de estándares de calidad o de gestión. La focalización de los esfuerzos en determinadas zonas y 
determinadas actuaciones es, a menudo, una cuestión de imagen de modo que la limitada disponibilidad de recursos predispone siempre a optar por actuaciones «visibles» por el mayor número posible de ciudadanos y con resultados a corto plazo.

Sin embargo, según se desprende de este análisis, se ha mostrado mucho menos interés en la preservación y/o rehabilitación de los ecosistemas litorales y de las funciones de protección que asegurarían la reducción de las pérdidas materiales en futuros episodios, ya que no han sido objeto de ninguna inversión, al menos de forma inmediata.

Una correcta gestión de este tipo de ambientes debería garantizar el correcto funcionamiento de todas las funciones descritas, con el objetivo final de restaurar la integridad de los sistemas litorales. Las iniciativas empleadas hasta ahora ante estas situaciones de riesgo son parciales y tienen una eficacia discutible como demuestra que año tras año los temporales siguen produciendo daños y éstos sean cada vez mayores. Según el informe EUROSION (2004) la inversión de fondos públicos en acciones de mitigación en zonas litorales va en aumento: 3.200 millones de $€$ en 2001 frente a los 2.500 en 1986 y, según estudios previos llevados a cabo por el Panel Intergubernamental de Naciones Unidas, alcanzarán 5.400 millones de €anuales entre 1990 y 2020. El propio informe reconoce que estas inversiones se centran en "proteger los bienes expuestos, pero no reflejan los costes inducidos por actividades humanas a largo plazo».

Lejos de considerar esta situación como una oportunidad para replantear el uso que se está haciendo de la "primera línea de playa», todo parece indicar que en el futuro inmediato no se van a modificar estos hábitos de uso y consumo de la franja litoral. Para la sociedad actual, los beneficios obtenidos de actividades situadas en zonas peligrosas, cuando no hay riesgo para la vida humana, compensa las pérdidas. Se trataría de una situación de riesgo rentable económicamente, sobre todo, cuando el coste de las pérdidas es asumido de forma colectiva por la sociedad (el Estado, CCS, etc.) mientras que los beneficios tienen una menor redistribución (Fernández Garrido, 2006). En resumen, se trataría de poner en marcha respuestas que resuelvan los conflictos entre los actores en juego, es decir, tanto los intereses particulares como el interés general, o lo que es lo mismo entre los valores económicos y los ambientales. Finalmente, todas las acciones de mitigación deberían estar sujetas a un análisis más riguroso en el que el adquiera mayor relevancia el papel de la información científica en la toma de decisiones relacionadas con el medio ambiente (Rivas et al., 1994; Fischer et al., 1995). Igualmente debería tenerse en consideración la ratio coste-beneficio evitando decisiones cuyas consecuen- 
cias ambientales sería preciso evaluar (Flor et al., 2014).

En cualquier caso, y de forma general, la estimación de los costos derivados de riesgos naturales implica una considerable incertidumbre debida a la escasez de fuentes de información y al carácter altamente agregado de los datos que ofrecen (Meyer et al., 2013). Por otro lado, también son necesarios estudios complementarios detallados sobre las características y evolución de los ambientes costeros que permita obtener un mejor conocimiento sobre los procesos que han originado el daño.

\section{BIBLIOGRAFÍA Y FUENTES}

André, C., Monfort, D., Bouzit, M. y Vinchon, C. (2013): "Contribution of insurance data to cost assessment of coastal flood damage to residential buildings: insights gained from Johanna (2008) and Xynthia (2010) storm events", Natural Hazards and Earth System Sciences, 13, pp. 2003-2012.

Ayala, F. y Olcina, J. (2002): Riesgos Naturales, Barcelona, Ariel, 1512 pp.

Berrisford, P., Dee, D., Poli, P., Brugge, R., Fielding, K., Fuentes, M., Kallberg, P., Kobayashi, S., Uppala, S. y Simmons, A. (2011): The ERA-Interim archive Version 2.0, Reading, ECMWF, 17 pp. ERA Report Series, 1.

Cendrero, A., Sánchez-Arcilla, A. y Zazo, C. (2005): "Impactos sobre las zonas costeras", en J. M. Moreno (dir.), Evaluación preliminar de los impactos en España por efecto del Cambio Climático, Proyecto ECCE, Madrid, Ministerio de Medio Ambiente, pp. 469-524.

Centro Nacional de Información Geográfica (2014): Líneas límite municipales. Longitud en metros de las líneas municipales costeras según su inscripción en el Registro Central de Cartografía, Madrid, Gobierno de España, Ministerio de Fomento, Instituto Geográfico Nacional, Servicio de Delimitaciones Territoriales, http://centrodedescargas.cnig.es/CentroDescargas/equipamiento.do?method=descargarEquipam iento\&codEquip=3 (fecha de consulta: 1/6/2014).

Chust, G., Borja, A., Liria, P., Galparsoro, I., Marcos, M., Caballero, A. y Castro, R. (2009): "Human impacts overwhelm the effects of sea-level rise on Basque coastal habitats (N Spain) between 1954 and 2004", Estuarine, Coastal and Shelf Science, 84, pp. 453-462.

Chust, G., Caballero, A., Marcos, M., Liria, P., Hernández, C. y Borja, Á. (2010): "Regional scenarios of sea level rise and impacts on Basque (Bay of Biscay) coastal habitats, throughout the 21st century", Estuarine, Coastal and Shelf Science, 87, pp. 113-124.

Cid, A., Menéndez, M., Castanedo, S., Abascal, A. J., Méndez, F. y Medina, R. (2015): "Long term changes in the frequency, intensity and duration of extreme storm surge events in southern Europe", Climate Dynamics, doi 10.1007/s00382-015-2659-1. 
Conde Criado, J. (2014): Episodios de oleaje intenso en las costas del Cantábrico durante el periodo octubre-1957 a marzo-2014, AEMet, http://www.aemet.es/documentos/ es/noticias/2014/Analisis_Episodios_Oleaje_Intenso_V4.pdf (fecha de consulta: $1 / 3 / 2014$ ).

Consorcio de Compensación de Seguros (2014a): Ámbitos de actividad, Riesgos extraordinarios, Madrid, Ministerio de Economía y Competitividad, http://www.consorseguros.es/web/ad_re (fecha de consulta: 1/7/ 2014).

Consorcio de Compensación de Seguros (2014b): Notas informativas sobre los embates de mar producidos en los primeros días del mes de febrero de 2014 en la costa cantábrica y Galicia, Madrid, Ministerio de Economía y Competitividad, http://www.consorseguros.es/web/le_n (fecha de consulta: 1/7/ 2014).

Constanza, R., D’Arge, R., Groot, R., Farber, S., Grasso, M., Hannon, B., Limburg, K., Naeem, S., O’Neill, R. V., Paruelo, J., Raskin, R. G., Sutton, P. y Belt, M. (1997): "The value of the world s ecosystem services and natural capital", Nature, 387, pp. 253-260.

Della-Marta, P. M. y Pinto, J. G. (2009): "Statistical uncertainty of changes in winter storms over the North Atlantic and Europe in an ensemble of transient climate simulations", Geophysical Research Letters, 36/L14703, 5 pp.

DGSCM, Dirección General de Sostenibilidad de la Costa y del Mar (2014): Plan Litoral. Obras de reparación por temporales, Madrid, Ministerio de Agricultura, Alimentación y Medio Ambiente, http://www.magrama.gob.es/es/costas/temas/planlitoral-obras-emergencia-temporales/default.aspx (fecha de consulta: 1/7/2014).

ECMWF (2014): ERA-Interim.Global atmospheric reanalysis, European Centre for Medium-Range Weather Forecasts (ECMWF), http://www.ecmwf.int/en/research/climate-reanalysis/era-interim (fecha de consulta: 1/3/2014).

EUROSION (2004): Vivir con la erosión costera en Europa. Sedimentos y espacio para la sostenibilidad, Directorate General Environmental European Commission, http://www.eurosion.org/project/eurosion_es.pdf (fecha de consulta: 1/3/2014).

Fernández Garrido, M. I. (2006): Los riesgos naturales en España y en la Unión Europea: incidencia y estrategias de actuación, tesis doctoral, Universidad de Cantabria, Departamento de Geografía, Urbanismo y O. T., Inédita, 750 pp.

Fischer, D. W., Rivas, V. y Cendrero, A. (1995): "Local government planning for coastal protection: a case study of cantabrian municipalities, Spain", Journal of Coastal Research, 11/3, pp. 858-874.

Flor, G., Flor-Blanco, G. y Flores-Soriano, C. (2014): "Cambios ambientales por los temporales de invierno de 2014 en la costa asturiana (NO de España)", Trabajos de Geología, 34, pp. 97-123.

INE (2014): Demografía y Población, http://www.ine.es/inebmenu/mnu_padron.htm (fecha de consulta: 1/3/2014).

Institut für Meteorolige (2014): Low Pressure Systems, Berlín, Freie Universität Berlin, http://www.met.fu-berlin.de/adopt-a-vortex/tief2014/ (fecha de consulta: 1/3/2015). Jordà, G., Gomis, D., Álvarez-Fanjul, E. y Somot, S. (2012): "Atmospheric contribu- 
tion to Mediterranean and nearby Atlantic sea level variability under different climate change scenarios", Global and Planetary Change, 80-81, pp. 198-214.

MAGRAMA (2013): "Guía de Playas de España. Base de Datos”, en Cartografía y SIG, Infraestructura de datos espaciales-Descargas, Madrid, Ministerio de Agricultura, Alimentación y Medio Ambiente, http://www.magrama.gob.es/es/cartografia-ysig/ide/descargas/costas-medio-marino/default.aspx (fecha de consulta: 1/3/2014).

Marcos, M., Chust, G., Jordà, G. y Caballero, A. (2012): "Effect of sea level extremes on the western Basque coast during the 21st century", Climate Research, 51, pp. 237-248.

Méndez, F. J., Menéndez, M., Luceño, A. y Losada, I. J. (2006): "Estimation of the long-term variability of extreme significant wave height using a time-dependent Peak Over Threshold (POT) model", Journal of Geophysical Research, 111/C07024, $13 \mathrm{pp}$.

Menéndez, M., Espejo, A., Pérez, J., Méndez, F. J. y Losada I. J. (2014): “Análisis climatológico de los temporales marítimos en la cornisa atlántica durante el invierno 2013-2014", Publicaciones de la Asociación Española de Climatología, serie A, 9, pp. 489-498.

Met Office (2014a): Weather summaries, Winter 2013/14, http://www.metoffice.gov.uk/ climate/uk/summaries/2014/winter (fecha de consulta: 1/3/2014).

Met Office (2014b): The Recent Storms and Floods in the UK, Met Office, Centre for Ecology \& Hydrology (CEH), Natural Environment Research Council, http://www.metoffice.gov.uk/media/pdf/n/i/Recent_Storms_Briefing_Final_07023.pdf (fecha de consulta: 1/3/2014).

Meyer, V., Becker, N., Markantonis, V., Schwarze, R., van den Bergh, J. C. J. M., Bouwer, L. M., Bubeck, P., Ciavola, P., Genovese, E., Green, C., Hallegatte, S., Kreibich, H., Lequeux, Q., Logar, I., Papyrakis, E., Pfurtscheller, C., Poussin, J., Przyluski, V., Thieken, A. H. y Viavattene, C. (2013): "Review article: Assessing the costs of natural hazards - state of the art and knowledge gaps", Natural Hazards and Earth System Sciences, 13, pp. 1351-1373.

Ministerio de Hacienda y Administraciones Públicas (2012): Evaluación de la Gestión y Funcionamientos de las Demarcaciones de Costas para la Protección del Dominio Público Marítimo-Terrestre en la perspectiva de su adecuación tanto a la Directiva Marco del Agua como a la Directiva Marco sobre Estrategia Marina, Madrid, Gobierno de España, Agencia Estatal de Evaluación de las Políticas Públicas y la Calidad de los Servicios (AEVAL), E28-2010, 233 pp.

Neumann B., Vafeidis A. T., Zimmermann J. y Nicholls R. J. (2015): "Future Coastal Population Growth and Exposure to Sea-Level Rise and Coastal Flooding - A Global Assessment", PLoS ONE, 10/3, e0118571, doi:10.1371/journal.pone. 0118571.

NOAA/ESRL (2014): Earth System Research Laboratory (ESRL), Boulder, Colorado, Physical Sciences Division, http://www.esrl.noaa.gov/psd/ (fecha de consulta: $1 / 3 / 2014)$. 
OSPAR Commission (2000): Quality Status Report 2000: Region IV - Bay of Biscay and Iberian Coast, London, OSPAR Commission, 134 + xiii pp.

Puertos del Estado (2014): Oceanografía, Previsión tiempo real y clima, Madrid, Ministerio de Fomento, http://www.puertos.es/es-es/oceanografia/Paginas/portus.aspx (fecha de consulta: 1/5/2014).

Rasilla, D. F., Garmendia, C., García Codrón, J. C. y Rivas, V. (2014): "Marine storms and coastal risk along the Gulf of Biscay area: winter 2014", en Associação Portuguesa de Riscos, Prevenção e Segurança (ed.), Multidimensao e territórios de Risco, Guimaraes (Portugal), Imprensa da Universidade de Coimbra, pp. 336- 342.

Real Decreto-Ley 2/2014: BOE, 46, pp. 17365-17375.

Rivas, V. (1991): Evolución reciente y estado actual del litoral cantábrico oriental, tesis doctoral, Universidad de Murcia, inédita, 537 pp.

Rivas, V. y Cendrero, A (1993): "Determination of the evolutionary condition of coastal cliffs on the basis of geological and geomorphological parameters", en Hans-Peter Plag (ed.), Proceedings of the International Coastal Congress - ICC, Kiel, pp. 214-222.

Rivas, V., Fischer, D. W. y Cendrero, A. (1994): "Perception of indicators of coastal environmental quality by municipal officials in northern Spain", International Journal of Environmental Studies, 45, pp. 217-225.

Wetterzentrale (2014): CFS Reanaysis: Informationen, http://www.wetterzentrale.de/ topkarten/fscfsreaeur.html (fecha de consulta: 1/3/2014).

Fecha de recepción: 31 de marzo de 2015.

Fecha de aceptación: 20 de octubre de 2015. 